\title{
Post-intensive care unit clinics in Canada: a national survey
}

\author{
Kallie Stapleton, MBBS (D) Matthew Jefkins, MD - Christopher Grant, MD, \\ FRCPC $\cdot$ J. Gordon Boyd, MD, PhD, FRCPC
}

Received: 14 January 2020/Revised: 26 May 2020/Accepted: 29 May 2020/Published online: 17 June 2020

(C) Canadian Anesthesiologists' Society 2020

\section{To the Editor,}

Post-intensive care unit syndrome (PICS) is defined as new or worsening impairment in physical, cognitive, or mental health status after critical illness that persists beyond the acute care setting. ${ }^{1}$ Post-intensive care unit syndrome is estimated to occur in $25-50 \%$ of intensive care unit (ICU) survivors. The recognition of this syndrome's impact on the quality of life for ICU survivors and their families has been the impetus to develop post-ICU clinics to diagnose and manage PICS. ${ }^{2}$

The purpose of our study was twofold. First, we wanted to identify the number of post-ICU clinics across Canada. Secondly, for established clinics, we aimed to understand the infrastructure and processes of care for PICS patients. Survey questions were generated by the study team based

Electronic supplementary material The online version of this article (https://doi.org/10.1007/s12630-020-01741-1) contains supplementary material, which is available to authorized users.

Kallie Stapleton and Matthew Jefkins have contributed equally to this work.

\footnotetext{
K. Stapleton, MBBS $(\bowtie)$.

Department of Critical Care, Queen's University, Kingston, ON, Canada

e-mail: 15kjs2@queensu.ca

M. Jefkins, MD

Department of Internal Medicine, Kingston, ON, Canada

C. Grant, MD, FRCPC

Division of Physical Medicine and Rehabilitation, University of

Calgary, Calgary, AB, Canada
}

J. G. Boyd, MD, PhD, FRCPC

Department of Critical Care Medicine, Department of

Neurology, Queen's University, Kingston, ON, Canada on previous research. ${ }^{3}$ Following item reduction, a 15question electronic survey (Qualtrics, Provo, UT, USA) was delivered to ICU managers across Canada (see eAppendix in the Electronic Supplementary Material). A list of the ICUs across Canada was obtained with permission from a study completed by Fowler et al. ${ }^{4}$ In total, 271 hospitals with adult ICUs were contacted via telephone to obtain the unit manager's email address; and 246 electronic surveys were distributed. Participation was optional and anonymous. Survey completion was encouraged with follow-up emails and telephone calls. No financial incentive was provided. Data were summarized with descriptive statistics.

The response rate was 52\%. Most ICUs had 6-10 beds $(n=36)$ or $11-20$ beds $(n=36)$. Referral to a post-ICU clinic was rare $(n=6)$; the six existing clinics were all established within the previous four years and receive referrals from medical/cardiac, neurologic/neurosurgical, surgical, and mixed ICUs (Figure). Few $(n=11)$ ICUs had plans to develop a post-ICU clinic. Clinic referral criteria included significant delirium (2/6), ICU stay greater than four or seven days (1/6 and $2 / 6$, respectively), extracorporeal life support (1/6), direct discharge home from the ICU (1/6), and invasive ventilation for four or more days (1/6). Referral exclusion criteria included palliative patients $(2 / 6)$, homelessness $(1 / 6)$, patients from outside the catchment area (1/6), and cognitive impairment that would preclude meaningful interactions (1/6). Timing of patient follow-up ranged from within three months to greater than six months following ICU discharge. Clinic patients were assessed by various healthcare providers including physicians (5/6), social workers (3/6), nurses (1/ 6), nurse practitioners (1/6) and pharmacists (1/6). Referrals were triggered by either ICU physicians or nurses. Clinic practices included counselling (4/6), 
Figure Post-ICU clinic referral by ICU subtype. A total of nine ICUs referred patients to six established post-ICU clinics. $\mathrm{ICU}=$ intensive care unit.
Post ICU Clinic

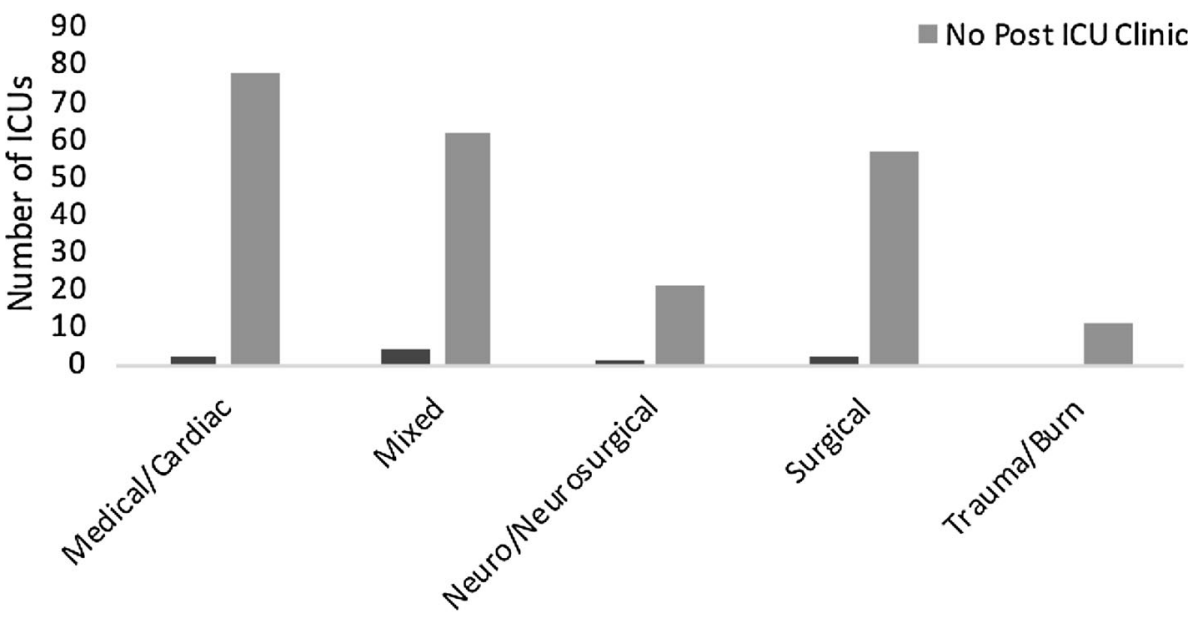

ICU Subtype education regarding the reason for ICU admission (3/6), reviewing metrics $(3 / 6)$, medication reconciliation $(3 / 6)$, physical examination (2/6), touring the ICU (2/6), and referral to rehabilitation resources $(1 / 6)$. The most common metrics used were the Montreal Cognitive Assessment (3/ 6 ) and the Impacts of Events Score (2/6). Most clinics saw between 0 and 50 patients a year, with one clinic seeing 151-200 patients annually.

A limitation to our study was the low response rate, which made our results an estimate of the current state of post-ICU care across Canada. The total number of postICU clinics in the country was small, limiting statistical analysis.

Now more than ever, intensive care and PICS are becoming part of the vernacular in both scientific and lay media. Our study highlights the lack of formal post-ICU follow-up care across Canada. The barriers to establishing these clinics are not known, but lack of resources (personnel, time) likely contributes. Many ICU survivors that have a constellation of new impairments are either lost to follow-up or do not have access to specialized care. ${ }^{1,4}$ Furthermore, ICU admission is associated with increased inpatient and emergency department resource utilization following discharge. ${ }^{5}$ Primary care providers are key in this process, but post-ICU clinics may bridge an important gap in care.

Disclaimer The views expressed in this article are not an official position of the associated institutions.
Disclosures John Gordon Boyd receives as stipend from the Trillium Gift of Life Foundation for his role as Regional Medical Lead. He receives salary support from the Southeastern Ontario Academic Medical Association New Clinician Scientist Program.

Funding statement None.

Editorial responsibility This submission was handled by Dr. Sangeeta Mehta, Associate Editor, Canadian Journal of Anesthesia.

\section{References}

1. Needham DM, Davidson J, Cohen H, et al. Improving long-term outcomes after discharge from intensive care unit: report from a stakeholders' conference. Crit Care Med 2012; 40: 502-9.

2. Elliott D, Davidson JE, Harvey MA, et al. Exploring the scope of post-intensive care syndrome therapy and care: engagement of non-critical care providers and survivors in a second stakeholders meeting. Crit Care Med 2014; 42: 2518-26.

3. Griffiths JA, Barber VS, Cuthbertson BH, Young JD. A national survey of intensive care follow-up clinics. Anaesthesia 2006; 61: 950-5.

4. Fowler RA, Abdelmalik $P$, Wood $G$, et al. Critical care capacity in Canada: results of a national cross-sectional study. Crit Care 2015; . https://doi.org/10.1186/s13054-015-0852-6.

5. Hirshberg EL, Wilson EL, Stanfield V, et al. Impact of critical illness on resource utilization: a comparison of use in the year before and after ICU admission. Crit Care Med 2019; 47: 1497504.

Publisher's Note Springer Nature remains neutral with regard to jurisdictional claims in published maps and institutional affiliations. 